
\title{
28 Research Suare \\ Do breastfeeding practices correlate with childhood diarrhoea? Multiple data analyses using national surveys in Ghana
}

Anthony Mwinilanaa Tampah-Naah ( $\sim$ atampah@uds.edu.gh )

Simon Diedong Dumbo University of Business and Integrated Development Studies

\section{Research}

Keywords: Breastfeeding, Practices, Children, Diarrhoea, Ghana

Posted Date: November 5th, 2020

DOI: https://doi.org/10.21203/rs.3.rs-22843/v2

License: (a) (1) This work is licensed under a Creative Commons Attribution 4.0 International License. Read Full License 


\section{Abstract}

Background: Breastfeeding as a natural intervention tends to have a protective effect on the occurrence of diarrhoea in children. In environments where breastfeeding is suboptimal coupled with the early introduction of complementary foods, children are at a higher risk of experiencing diarrhoea. This study examined whether breastfeeding practices are associated with childhood diarrhoea in Ghana using multiple secondary datasets.

Methods: The study used data from Ghana Demographic and Health Survey (GDHS) 2003, 2008 and 2014 individual datasets. These datasets contain data on women and issues related to children who were two years of age (0-23 months). An appended weighted sample of 4,675 mother-child pairs was used for the analyses. Thus, logistic regression analyses were performed to assess the effect of explanatory variables that were considered as potential confounders on the association between breastfeeding practices and childhood diarrhoea.

Results: Univariate analysis revealed that children who were not exclusively breastfeeding had higher odds of experiencing diarrhoea. With the multilevel logistic analysis, breastfeeding practices and risks of diarrhoea among children revealed significant associations.

Conclusions: Findings for this study further affirms to the protective effect breastfeeding has against childhood diarrhoea. Exclusive breastfeeding and at times predominant breastfeeding could prevent or minimize diarrhoea compare to non-practice of breastfeeding or partial breastfeeding.

\section{Introduction}

Infectious diseases among children are accorded much public health attention due to their adverse impact on their growth and development. And diarrhoea is one of the leading causes of morbidity and mortality among children worldwide with much of its burden being accounted for by less developed and resource-poor countries [1]. Projections show that diarrhoea contributed to about nine per cent of all deaths among children under age five; thus being the second highest cause of childhood mortality [2]. In a cohort study consisting of 18,819 infants, optimal breastfeeding was associated with a 53 per cent decrease in hospital admissions for diarrhoea [3].

National surveys conducted in Ghana suggest that a decline, although still high, in the prevalence of diarrhoea; from $19.8 \%$ in 2008 to $12 \%$ in 2014 [4-6]. However, the same surveys have documented decrease in the rates of exclusive breastfeeding (63\% in 2008 to $54 \%$ in 2014) and increase in the introduction of complementary foods (68\% in 2008 to $88 \%$ in 2014) to children. This certainly means that more infants and young children are being introduced to complementary foods early that reduced the exclusive breastfeeding rate, and that still maintained a high prevalence of diarrhoea among the children. The slight decline in diarrhoea and the downward and upward rates of exclusive and complementary feeding, respectively, suggests the interplay of some confounding factors. And in situations where complementary foods are contaminated or are not nutritionally balanced, infants and young children are most likely to be exposed to morbidities such as diarrhoea.

Notwithstanding the contributions made by studies $[7,8]$ to child health and nutrition literature, less attention has been paid to breastfeeding practices, of mothers with children less than two years, which is a key variable in early childhood infections pathways. At best, where breastfeeding is considered, it is presented as a confounding variable including others. Yet, breastfeeding practices of children are pre-requisite to their positive growth and development, health, and survival [9]. In this study was intended to respond to the question of whether breastfeeding practices correlate with diarrhoea among infants and young children. 
The study sought to assess breastfeeding practices and risks of childhood diarrhoea in Ghana using separate datasets from the Ghana Demographic and Health Surveys (GDHS) conducted in years of 2003, 2008 and 2014 . It considered potential factors at the individual-level, community-level, health-level and environmental-level to accomplish its purpose. Findings of the study would add new insights to the interactions between breastfeeding practices and diarrhoea by holding constant some pertinent factors in the areas of child health and nutrition.

\section{Methods}

\section{Study data and sample group}

The study used data from GDHS. More information about the surveys can be found at https://dhsprogram.com. The specific data used in this study were from the GDHS 2003, 2008 and 2014 individual datasets. These datasets contain data on women and issues related to children. Analyses were restricted to mothers (15-49 years) who had a child less than two years of age (0-23 months) and that child should have been living with the mother at the time of the survey. The GDHS datasets are publicly available at http://dhsprogram.com/data/dataset/Ghana from which data for this paper were obtained, and Measure DHS approved a concept note before the datasets were downloaded. The specific data used in this study was the various survey years' individual datasets. These datasets contain details on, but not limited to, mothers characteristics, breastfeeding practices and childhood morbidity (diarrhoea). An appended weighted sample of 4,675 mother-child pairs was used for the analyses (Table 1). Also, more about the sample procedures used in the GDHS are available at http://www.dhsprogram.com/publications/publication-FR307-DHS-Final-Reports.cfm.

\section{Table 1: Sample group}

\begin{tabular}{llll}
\hline Age & \multicolumn{3}{c}{ Survey year } \\
\cline { 2 - 4 } & 2003 & 2008 & 2014 \\
\hline $0-5$ & $307(26.15)$ & $307(26.14)$ & $561(47.71)$ \\
$6-11$ & $370(29.68)$ & $297(23.81)$ & $579(46.51)$ \\
\hline $12-23$ & $662(29.38)$ & $530(23.50)$ & $1062(47.12)$ \\
\hline Total & $1339(28.64)$ & $1134(24.25)$ & $2202(47.11)$ \\
\hline
\end{tabular}

$N=4675$

\section{Exposure variable}

The exposure variable, breastfeeding practice(s), which is hierarchically and mutually exclusive, was coded as no breastfeeding $=0$; exclusive breastfeeding $=1$; predominant breastfeeding $=2$; and partial breastfeeding $=3$. These categories are defined as follows, within 24 hours preceding each survey: (i) no breastfeeding - children were not breastfeeding; (ii) exclusive breastfeeding - children were only fed with breast milk; (iii) predominant breastfeeding - children were breastfed with breast milk including plain water, non-milk liquids and other milk; and (iv) partial breastfeeding - children were fed with breast milk plus complementary foods.

\section{Outcome variables}

The outcome variable was diarrhoea. Data on 'all diarrhoea' and 'diarrhoea with blood' were collected. Mothers were asked, "Whether any of their children under five years of age had diarrhoea during the two weeks preceding the survey". The responses to this question were: No=0; Yes, last two weeks=1; Don't know=8. All the "Don't Know" 
responses on the dependent variables were excluded from the analysis. This was done because the study was only interested in responses that were captured on either a child had diarrhoea or no diarrhoea. The outcome variable was dichotomized, with $\mathrm{No}=\mathrm{O}$ and $\mathrm{Yes}=1$ format.

\section{Explanatory variables}

The review of related literature and extensive data mining informed the choice of afore-mentioned explanatory variables. These variables included: maternal education, working status, place of residence, preceding birth interval, source of drinking water, type of toilet facility, and type of floor material. The explanatory variables were arbitrarily assigned numeric codes starting with either ' $O$ ' or ' 1 '.

Maternal education was categorized into no education, primary, and secondary or higher. For the preceding birth interval, births of mothers were recoded into those who had less than 24 months and those of 24 months or more. Environmental variables that may help explain diarrhoea episodes in children include a source of drinking water, type of toilet facility, and type of floor material. The various responses given by mothers, in the aforementioned variables, were recoded as either 'improved' or 'unimproved'. Responses for source of drinking water were categorized as follows: improved sources (piped into dwelling, piped to yard/plot, public tap or standpipe, tube-well or borehole, protected well, protected spring, rainwater); and unimproved sources (unprotected spring, unprotected well, river/dam/lake/ponds/stream/canal/irrigation, tanker-truck, cart with small tank, bottled water sachet).

For type of toilet facility, improved facilities included flush to piped sewer system, flush to septic tank, flush to pit latrine, flush to somewhere else, ventilated improved pit latrine (VIP), pit latrine with slab, composting toilet, and a special case (i.e., flush/pour flush of excreta to a place unknown to the respondent); and unimproved facilities consisted of flush/pour flush to elsewhere (such as street, yard/plot, open sewer or a ditch), pit latrine without slab, bucket, hanging toilet or hanging latrine, shared sanitation, no facilities, bush or field). The above categorizations are in accordance to World Health Organisation (WHO) and United Nations Children's Fund (UNICEF) Joint Monitoring Programme (JMP) for Water and Sanitation [10].

Furthermore, type of floor material was grouped as improved (tablets/wood/planks, palm/bamboo, mat, adobe, parquet/polished wood, vinyl/asphalt strips/ floor mat, linoleum, ceramic tiles/mosaic, cement, carpet, stone, bricks); and unimproved (earth, sand, clay, mud, dung). These categorizations conform with the Demographic and Health Surveys (DHS) programme [11].

\section{Data analysis}

Prevalence rates of diarrhoea were initially examined among the explanatory variables and the chi-square test of independence was used to identify significant associations. Only independent variables that had a $p$-value less than 0.25 at the chi-square test were considered for the logistic regression. Applying hierarchical logistic regression modelling procedures, categories of significant factors associated with diarrhoea were ascertained. To finally examine the interactive nature of the outcome, exposure and explanatory variables, a single multilevel logistic modelling approach was applied. Thus, logistic regression analyses were performed to assess the effect of explanatory variables that were considered as potential confounders on the association between breastfeeding practices and childhood diarrhoea. Essentially, the various explanatory variables were nested in the exposure variable to estimate their effect on each of the outcome variable (diarrhoea). Probability values ( $p$-values) of 0.01 , 0.05 and 0.001 were used to establish significant associations. In generating these models, clustering effects were accounted by prefixing each STATA command with svy to estimate for robust standard errors. A survey design 
weight of v005, primary sampling unit of v021 and strata of v023 were used in the survey set statement. Results were presented in odds ratios and 95\% Confidence Interval (CI) STATA (version 12.0) was used to process the data.

\section{Results}

\section{Age of child (0-23 months) and breastfeeding practices}

Fig. 1 shows the prevalence of breastfeeding practices among children aged 0-23 months. A gradual increase in numbers from the middle ages towards the last ages were not breastfeeding. An opposite pattern was observed with those who were exclusively breastfeeding. Thus, exclusive breastfeeding rates from birth starts to decrease steadily as the children grow old. Predominant breastfeeding is common among children aged 0-6 months and then starts to decrease steadily as they grow older. The occurrence of partial breastfeeding is normally distributed among the children and much of the partial breastfeeding practices are heaped in the middle ages.

\section{Prevalence of diarrhoea among children (0-23 months)}

From preliminary analysis, the prevalence rate of diarrhoea was 13 per cent among the children. The results further indicate that maternal education, working status, place of residence, source of drinking water, and type of toilet facility were statistically associated with diarrhoea.

Slightly more than two-fifth of children whose mothers had no education (20\%) and 15 per cent of those with secondary or higher levels of education reported childhood diarrhoea episodes (Table 2). A higher prevalence of diarrhoea cases was observed among children whose mothers were working. Also, the proportion of diarrhoea among children in rural areas was 20 per cent compared with 15 per cent in urban areas. The prevalence of diarrhoea was higher among children with mothers who had access to an improved source of drinking water (19\%) compared with those who had access to an unimproved source of drinking water (15\%). A higher proportion of diarrhoea was linked with children whose mothers had access to unimproved toilet facilities (21\%) than those who had access to improved toilet facilities (16\%) (Table 2).

Table 2: Prevalence of diarrhoea among mother-child pairs (0-23 months) for all years 


\begin{tabular}{|c|c|c|c|}
\hline \multirow[t]{2}{*}{ Variable } & \multirow[t]{2}{*}{$p$-value } & \multicolumn{2}{|c|}{ Reported cases of diarrhoea } \\
\hline & & $\mathrm{n}$ & $\%$ \\
\hline Maternal education & $0.0016^{* * *}$ & & \\
\hline No education & & 304 & 20.41 \\
\hline Primary & & 195 & 19.74 \\
\hline Secondary/Higher & & 337 & 15.37 \\
\hline Working status & $0.4539 *$ & & \\
\hline Not working & & 156 & 16.91 \\
\hline Working & & 679 & 18.16 \\
\hline Place of residence & $0.0121^{* * *}$ & & \\
\hline Urban & & 288 & 15.47 \\
\hline Rural & & 548 & 19.52 \\
\hline Preceding birth interval & 0.2128 & & \\
\hline Less than 24 months & & 68 & 15.83 \\
\hline 24 months or more & & 592 & 18.44 \\
\hline Source of drinking water & $0.0014^{*}$ & & \\
\hline Improved & & 542 & 19.13 \\
\hline unimproved & & 204 & 14.54 \\
\hline Type of toilet facility & $0.0002 * * *$ & & \\
\hline Improved & & 468 & 15.87 \\
\hline Unimproved & & 368 & 21.42 \\
\hline Type of floor material & 0.1463 & & \\
\hline Improved & & 631 & 17.41 \\
\hline Unimproved & & 206 & 19.63 \\
\hline
\end{tabular}

*: $p<0.01 ; * *: p<0.05 ; * * *: p<0.001$

\section{Breastfeeding practices and risks of diarrhoea among children (0-23 months)}

The multilevel logistic analysis of breastfeeding practices and risks of diarrhoea among children revealed significant associations (Table 3). In the models for each survey year, even upon controlling for potential explanatory variables, breastfeeding practices were significantly linked to diarrhoea cases among children. The results presented hereafter are based on the models generated from pooled data from all the survey years $(2003,2008$ and 2014). Univariate analysis revealed that children who were not exclusively breastfeeding had higher odds of experiencing diarrhoea. These categories of children most likely exposed to diarrhoea included those who were not breastfeeding $(\mathrm{OR}=3.120,95 \% \mathrm{Cl}=2.019,4.820)$, predominantly breastfeeding $(\mathrm{OR}=1.824$, $95 \% \mathrm{Cl}=1.198,2.777)$, and partially breastfeeding $(\mathrm{OR}=2.795,95 \% \mathrm{Cl}=1.931,4.047)$. This pattern of results was reflective in the final when other variables were held constant. Aside children who were exclusively breastfeeding (as a reference group), those not breastfeeding $(\mathrm{OR}=3.382,95 \% \mathrm{Cl}=2.084,5.490)$ had the highest odds ratio of reported cases of diarrhoea followed by those partially breastfeeding $(\mathrm{OR}=2.899,95 \% \mathrm{Cl}=1.965,4.278)$ and the last group were those predominantly breastfeeding $(\mathrm{OR}=1.684,95 \% \mathrm{Cl}=1.059,2.676)$.

For a place of residence, rural mothers $(\mathrm{OR}=1.310,95 \% \mathrm{Cl}=1.045,1.643)$ had higher odds of reported cases of diarrhoea among their children compared to their urban counterparts (Table 3). Children whose mothers had a preceding birth interval of 24 months or more $(\mathrm{OR}=1.384,95 \% \mathrm{Cl}=0.987,1.939)$ had a slightly higher likelihood of having diarrhoea compared to mothers with preceding birth intervals less than 24 months. Likewise, concerning mothers who had access to improved sources of water, children whose mothers used unimproved sources of drinking water had lower odds of having diarrhoea $(\mathrm{OR}=0.726,95 \% \mathrm{Cl}=0.580,0.910)$. The likelihood for the 
occurrence of childhood diarrhoea was higher among mother-child pairs who used unimproved toilet facilities (OR $=1.442,95 \% \mathrm{Cl}=1.156,1.799)$.

Multilevel logistic regression modelling for breastfeeding practices and the risk of diarrhoea 


\begin{tabular}{|c|c|c|c|c|c|c|c|c|}
\hline \multirow[t]{3}{*}{ Variable } & \multicolumn{8}{|c|}{ Diarrhoea cases } \\
\hline & \multicolumn{2}{|c|}{2003} & \multicolumn{2}{|c|}{2008} & \multicolumn{2}{|c|}{2014} & \multicolumn{2}{|c|}{ All survey years } \\
\hline & Model I & Model II & Model I & Model II & Model I & Model II & Model I & Model II \\
\hline \multicolumn{9}{|l|}{$\begin{array}{l}\text { Breastfeeding } \\
\text { practices }\end{array}$} \\
\hline $\begin{array}{l}\text { Exclusive BF } \\
\text { No BF } \\
\text { Predominant BF } \\
\text { Partial BF }\end{array}$ & $\begin{array}{l}1 \\
9.722^{* * *} \\
(4.382, \\
21.57) \\
6.139 * * * \\
(2.948, \\
12.785) \\
7.590 * * * \\
(3.940, \\
14.622)\end{array}$ & $\begin{array}{l}1 \\
6.290 * * * \\
(2.182, \\
18.131) \\
3.893 * \\
(1.380, \\
10.983) \\
5.677 * * * \\
(2.378, \\
13.549)\end{array}$ & $\begin{array}{l}1 \\
3.562 * * * \\
(1.917,6.618) \\
2.353^{*} \\
(1.189,4.654) \\
2.832 * * * \\
(1.694,4.734)\end{array}$ & $\begin{array}{l}1 \\
3.656 * * * \\
(1.755,7.617) \\
2.149 * \\
(1.075,4.297) \\
2.877 * * * \\
(1.675,4.944)\end{array}$ & $\begin{array}{l}1 \\
2.800 * * \\
{[1.370,5.723]} \\
2.839 * * \\
{[1.348,5.976]} \\
2.914 * * * \\
{[1.577,5.383]}\end{array}$ & $\begin{array}{l}1 \\
3.495^{*} \\
{[1.541,7.924]} \\
2.345^{* *} \\
{[1.013,5.426]} \\
3.236^{* * *} \\
{[1.617,6.474]}\end{array}$ & $\begin{array}{l}1 \\
3.120 * * * \\
{[2.019,4.820]} \\
1.824 * * \\
{[1.198,2.777]} \\
2.795 * * * \\
{[1.931,4.047]}\end{array}$ & $\begin{array}{l}1 \\
3.382 * * * \\
{[2.084,5.490]} \\
1.684 * * \\
{[1.059,2.676]} \\
2.899 * * * \\
{[1.965,4.278]}\end{array}$ \\
\hline \multicolumn{9}{|l|}{ Maternal education } \\
\hline $\begin{array}{l}\text { No education } \\
\text { Primary } \\
\text { Secondary/Higher }\end{array}$ & $\begin{array}{l}\text { n.a. } \\
\text { n.a. } \\
\text { n.a. }\end{array}$ & $\begin{array}{l}1 \\
1.862 * * \\
(1.066, \\
3.254) \\
1.310 \\
(0.757 \\
2.268)\end{array}$ & $\begin{array}{l}\text { n.a. } \\
\text { n.a. } \\
\text { n.a. }\end{array}$ & $\begin{array}{l}1 \\
0.829 \\
(0.559,1.272) \\
0.820 \\
(0.521,1.310)\end{array}$ & $\begin{array}{l}\text { n.a. } \\
\text { n.a. } \\
\text { n.a. }\end{array}$ & $\begin{array}{l}1 \\
0.692 \\
{[0.425,1.126]} \\
0.711 \\
{[0.485,1.042]}\end{array}$ & $\begin{array}{l}\text { n.a. } \\
\text { n.a. } \\
\text { n.a. }\end{array}$ & $\begin{array}{l}1 \\
0.924 \\
{[0.709,1.204]} \\
0.785 \\
{[0.608,1.015]}\end{array}$ \\
\hline \multicolumn{9}{|l|}{ Working status } \\
\hline $\begin{array}{l}\text { Not working } \\
\text { Working }\end{array}$ & $\begin{array}{l}\text { n.a. } \\
\text { n.a. }\end{array}$ & $\begin{array}{l}1 \\
0.928 \\
(0.454 \\
1.897)\end{array}$ & $\begin{array}{l}\text { n.a. } \\
\text { n.a. }\end{array}$ & $\begin{array}{l}1 \\
0.603 \\
(0.347,1.048)\end{array}$ & $\begin{array}{l}\text { n.a. } \\
\text { n.a. }\end{array}$ & $\begin{array}{l}1 \\
0.683 \\
{[0.451,1.035]}\end{array}$ & $\begin{array}{l}\text { n.a. } \\
\text { n.a. }\end{array}$ & $\begin{array}{l}1 \\
0.816 \\
{[0.610,1.093]}\end{array}$ \\
\hline \multicolumn{9}{|l|}{ Residence } \\
\hline $\begin{array}{l}\text { Urban } \\
\text { Rural }\end{array}$ & $\begin{array}{l}\text { n.a. } \\
\text { n.a. }\end{array}$ & $\begin{array}{l}1 \\
0.970 \\
(0.566 \\
1.662)\end{array}$ & $\begin{array}{l}\text { n.a. } \\
\text { n.a. }\end{array}$ & $\begin{array}{l}1 \\
1.345 \\
(0.816,2.215)\end{array}$ & $\begin{array}{l}\text { n.a. } \\
\text { n.a. }\end{array}$ & $\begin{array}{l}1 \\
1.305 \\
{[0.918,1.856]}\end{array}$ & $\begin{array}{l}\text { n.a. } \\
\text { n.a. }\end{array}$ & $\begin{array}{l}1 \\
1.310 * \\
{[1.045,1.643]}\end{array}$ \\
\hline \multicolumn{9}{|l|}{$\begin{array}{l}\text { Preceding birth } \\
\text { interval }\end{array}$} \\
\hline $\begin{array}{l}<24 \text { months } \\
\geq 24 \text { months }\end{array}$ & $\begin{array}{l}\text { n.a. } \\
\text { n.a. }\end{array}$ & $\begin{array}{l}1 \\
1.294 \\
(0.649, \\
2.579) \\
\end{array}$ & $\begin{array}{l}\text { n.a. } \\
\text { n.a. }\end{array}$ & $\begin{array}{l}1 \\
0.939 \\
(0.573,1.537)\end{array}$ & $\begin{array}{l}\text { n.a. } \\
\text { n.a. }\end{array}$ & $\begin{array}{l}1 \\
2.065^{* *} \\
{[1.082,3.942]}\end{array}$ & $\begin{array}{l}\text { n.a. } \\
\text { n.a. }\end{array}$ & $\begin{array}{l}1 \\
1.384 * * \\
{[0.987,1.939]}\end{array}$ \\
\hline \multicolumn{9}{|l|}{$\begin{array}{l}\text { Source of drinking } \\
\text { water }\end{array}$} \\
\hline $\begin{array}{l}\text { Improved } \\
\text { unimproved }\end{array}$ & $\begin{array}{l}\text { n.a. } \\
\text { n.a. }\end{array}$ & $\begin{array}{l}1 \\
1.065 \\
(0.640 \\
1.772) \\
\end{array}$ & $\begin{array}{l}\text { n.a. } \\
\text { n.a. }\end{array}$ & $\begin{array}{l}1 \\
0.985 \\
(0.645,1.504)\end{array}$ & $\begin{array}{l}\text { n.a. } \\
\text { n.a. }\end{array}$ & $\begin{array}{l}1 \\
0.605^{*} \\
{[0.423,0.867]}\end{array}$ & $\begin{array}{l}\text { n.a. } \\
\text { n.a. }\end{array}$ & $\begin{array}{l}1 \\
0.726^{*} \\
{[0.580,0.910]}\end{array}$ \\
\hline \multicolumn{9}{|l|}{$\begin{array}{l}\text { Type of toilet } \\
\text { facility }\end{array}$} \\
\hline $\begin{array}{l}\text { Improved } \\
\text { Unimproved }\end{array}$ & $\begin{array}{l}\text { n.a. } \\
\text { n.a. }\end{array}$ & $\begin{array}{l}1 \\
1.370 \\
(1.873, \\
2.148) \\
\end{array}$ & $\begin{array}{l}\text { n.a. } \\
\text { n.a. }\end{array}$ & $\begin{array}{l}1 \\
1.357 \\
(0.940,1.973)\end{array}$ & $\begin{array}{l}\text { n.a. } \\
\text { n.a. }\end{array}$ & $\begin{array}{l}1 \\
1.609 * * \\
{[1.114,2.324]}\end{array}$ & $\begin{array}{l}\text { n.a. } \\
\text { n.a. }\end{array}$ & $\begin{array}{l}1 \\
1.442^{* *} \\
{[1.156,1.799]}\end{array}$ \\
\hline \multicolumn{9}{|l|}{$\begin{array}{l}\text { Type of floor } \\
\text { material }\end{array}$} \\
\hline $\begin{array}{l}\text { Improved } \\
\text { Unimproved }\end{array}$ & $\begin{array}{l}\text { n.a. } \\
\text { n.a. }\end{array}$ & $\begin{array}{l}1 \\
1.820 * * \\
(1.082, \\
3.062)\end{array}$ & $\begin{array}{l}\text { n.a. } \\
\text { n.a. }\end{array}$ & $\begin{array}{l}1 \\
1.234 \\
(0.831,1.831)\end{array}$ & $\begin{array}{l}\text { n.a. } \\
\text { n.a. }\end{array}$ & $\begin{array}{l}1 \\
0.879 \\
{[0.581,1.328]}\end{array}$ & $\begin{array}{l}\text { n.a. } \\
\text { n.a. }\end{array}$ & $\begin{array}{l}1 \\
1.222 \\
{[0.968,1.543]}\end{array}$ \\
\hline
\end{tabular}


*: $p<0.01$;*: $p<0.05 ; * * *: p<0.001 ; B F$ : breastfeeding

\section{Discussion}

There is available evidence to show that breastfeeding minimizes the risk of diarrhoea among children [12, 13, 14]. The practice of optimum breastfeeding lessens exposure of infants from consuming other fluids and foods that may be unwholesome especially resource poor societies and hence children's' immune systems are fortified adequately to counteract any infections that may lead to diarrhoea [15]. This assertion was confirmed in the present study and some statistically significant covariates were found to be associated with the extend of breastfeeding and occurrence of diarrhoea.

Studies in sub-Saharan Africa have documented the protective effect breastfeeding has on the occurrence of diarrhoea among children $[16,17]$. Findings from this study indicated that exclusive breastfeeding had a protective effect on the occurrence of childhood diarrhoea. Thus, children who were not breastfeeding, predominant breastfeeding, and partial breastfeeding were at a much higher risk of contracting diarrhoea than those who were exclusively breastfed. The protective effect of breastfeeding was still evident after controlling for other potential factors. This suggests that breastfeeding could minimize episodes of childhood diarrhoea, other factors overshadow this effect. Probably, mothers or caregivers do not comply with breastfeeding recommendations or with basic hygienic processes in feeding children thereby creating a conducive environment for diarrhoea causing pathogens. In other instances, although children may be exclusively breastfeeding adequately, diarrhoea may occur especially when the foods are contaminated or not well prepared.

Moreover, the environment in which exclusive breastfeeding children live could predispose them to some morbidity; either in an urban area or in a rural setting. Place of residence, as an indirect factor, was found to be significantly associated with diarrhoea in this study. Children in rural areas were much burdened with the occurrence of diarrhoea. For instance, the consumption of contaminated foods, drinking of un improved water, poor handling of water, poor socio-economic status, lack of proper sanitation and poor hygiene are some factors deemed to individually or collectively overshadow the protective effect of exclusive breastfeeding, therefore, contributing to higher prevalence of diarrhoea in rural environments [18]. Although diarrhoea cases are common in urban areas especially in urban slums, children in rural areas are more disadvantaged [19]. Most rural areas in the country are noted for unfavourable health and environmental conditions and are also associated with cultural beliefs that may act as agents for the frequent occurrence of childhood diarrhoea [20,21].

A birth interval of a mother is critical to determining the health outcomes of her children. A finding showed that the preceding birth interval of a mother was significantly associated with reported episodes of diarrhoea among children. As documented by Fotso, Cleland, Mberu, Mutua and Elungata [22] in Kenya, shorter preceding birth interval tends to lessen the time required for a mother to adequately feed younger children and that could lead to diarrhoeal morbidity and mortality. Children whose mothers had a preceding birth interval of 24 months or more were more likely to have episodes of diarrhoea. This is intriguing since such breastfeeding mothers are deemed to have ample time to cater to their children. On the contrary, children with a previous birth interval of less than 18 months had a higher risk of dying from certain causes of death, including sepsis and diarrhoea than children with a previous birth interval of 24-35 months [23]. For this reason, education programmes on birth spacing tailored into activities of nurses at the various community-based planning and services compounds should be beneficial to the health of children to all mothers despite their preceding birth interval. 
It has been asserted that infants who are partially breastfed have higher odds of experiencing diarrhoea compared to those exclusively breastfed [24]. Even at instances where children are optimal breastfed and given unwholesome water, they would be at risk of diarrhoeal infections. It was found that the source of drinking water used by breastfeeding mothers contributed to childhood diarrhoea. Unimproved sources of water that are mostly contaminated account for a high proclivity of exposing children to diarrhoeal diseases. Elsewhere, studies have found that the use of an unimproved source of drinking water is associated with diarrhoea among infants and young children $[25,26]$. Continuously educating mothers on the fact that breastmilk contains 80 per cent and exclusively breastfed children do not need to drink water would be imperative to curtailing diarrhoea cases. It would also be necessary for household visitations to be made by community nurses to educated mothers practising sub-optimal breastfeeding to use improved sources of water or carefully treat unimproved water sources before using them to prepare complementary foods for their children.

Children with mothers who used unimproved toilet facilities had higher odds of experiencing diarrhoea. This implies that during optimal breastfeeding, children would still have higher chances of experiencing diarrhoea if their households use unimproved toilet facilities. The usage of unimproved toilet facilities could expose mothers to getting in contact with diarrhoeal pathogens. At instances where mothers do not practice adequate personal hygiene, they can transmit these pathogens to their children in the process of breastfeeding, handling or preparing complementary foods. Even how the stools of children are disposed in unimproved toilets equally is a pathway to childhood diarrhoeal episodes.

The main strength of this study is that it used a large nationally representative data set to analyze breastfeeding practices and childhood diarrhoea in the country. This was done using various variables at the individual, community, health, and environmental levels. Notwithstanding these strengths, limitations embedded in this study include the inability of it to assign any causality to its findings. Also, there is likely to be a recall bias since mothers reported diarrhoea cases within the last two weeks preceding the surveys. Besides, the prevalence of diarrhoea may vary seasonally and data for this study were collected between September and December, hence, interpretation of results should be linked to this period. To present or minimize the limitations outlined, it would be prodent, in future, to conduct longitudinal cohort studies on breastfeeding practices and childhood diarrhoea among children less than two years.

\section{Conclusions}

Conclusively, the findings of this study further reveal that breastfeeding especially exclusive breastfeeding has a protective effect on childhood diarrhoea. Potentially, place of residence, preceding birth interval, source of drinking water, and type of toilet facility of breastfeeding children can interfere with the protective effect of breast milk on the occurrence of diarrhoea in children. It would be prudent for local health authorities to reinforce measures or implement situational based interventions to curtail the negative effects of factors that can predispose children to diarrhoea episodes. Educational programmes such as peer-supports could potentially encourage mothers to appropriately practice optimal breastfeeding to ensure the occurrence of childhood diarrhoea would be minimized or prevented.

\section{Abbreviations}

$\mathrm{Cl}$ - Confidence Interval 
DHS - Demographic and Health Survey

ICF -

JMP - Joint Monitoring Program

UNICEF - United Nations Children's Fund

WHO - World Health Organisation

\section{Declarations}

\section{Ethical approval and consent to participate}

Ethics review committees of Ghana Statistical, Ghana Health Service in Ghana including ICF International's institutional review board gave ethical approval for the Demographic and Health Surveys (DHS) to be conducted in Ghana. Informed consent was sought from each respondent during the survey. Permission to use the data set was gotten from MEASURE DHS.

\section{Consent for publication}

Not applicable

\section{Availability of data and material}

The datasets analysed during the current study are available in the MEASURE DHS repository, https://dhsprogram.com/data/available-datasets.cfm

Competing interests: The author declares that they he has no competing interests.

Funding: No financial or nonfinancial benefits have been received or will be received from any party related directly or indirectly to the subject of this article.

Author's contribution: The corresponding author conceived the study, obtained needed data, conducted analysis and wrote the paper.

\section{Acknowledgements}

I thank Measure DHS for the data sets used for analysis. I would also thank Prof. Akwasi Kumi-Kyereme and Dr. Joshua Amo-Adjei (both of the Department of Population and Health, University of Cape Coast, Ghana) for their supportive review comments towards the write-up of this paper.

\section{References}

1. World Health Organization [WHO]. Diarrhoeal disease. 2017. http://www.who.int/news-room/factsheets/detail/diarrhoeal-disease. Accessed 20 Feb 2019.

2. United Nations Children's Fund [UNICEF]. Breastfeeding: Impact on child survival and global situation. 2015. http://www.unicef.org/nutrition/index_24824.html. Accessed 20 Feb 2019. 
3. Quigley MA, Kelly YJ, Sacker, A. Breastfeeding and hospitalization for diarrheal and respiratory infection in the United Kingdom Millennium Cohort study. 2007. Pediatrics, 119(4), e837-e842.

4. Ghana Statistical Service (GSS), Ghana Health Service (GHS), and ICF Macro. Ghana Demographic and Health Survey 2008. Accra, Ghana: GSS, GHS, and ICF Macro; 2004

5. Ghana Statistical Service (GSS), Ghana Health Service (GHS), and ICF Macro. Ghana Demographic and Health Survey 2008. Accra, Ghana: GSS, GHS, and ICF Macro; 2009

6. Ghana Statistical Service (GSS), Ghana Health Service (GHS), and ICF International. Ghana Demographic and Health Survey 2014. Accra, Ghana: GSS, GHS, and ICF International. 2015

7. Ewusie JE, Ahiadeke C, Beyene J, Hamid JS. Prevalence of anemia among uder-5 children in the Ghanaian population: estimates from the Ghana Demographic and Health Survey. 2014. BMC Public Health, 14, 626.

8. Nonvignon J, Aikins MK S, Chinbuah MA, Abbey M, Gyapong M, Garshong BNA, Fia S, Gyapong JO. Treatment choices for fevers in children under-five years in a rural Ghanaian district. 2010. Malaria Journal, 9, 188.

9. WHO/UNICEF. Global strategy for infant and young child feeding. WHO Press, Geneva, Switzerland: Author.

10. WHO \& UNICEF. Joint Monitoring Programme for Water Supply, Sanitation and Hygiene. 2009.

http://www.unwater.org/publication_categories/ whounicef-joint-monitoring-programme-for-water-supplysanitation-hygiene-jmp/. Accessed on 15 April, 2019.

11. Florey L, Taylor C. Using household survey data to explore the effects of improved housing conditions on malaria infection in children in sub-Saharan Africa. DHS Analytical Studies No. 61. 2016. Rockville, Maryland, USA: ICF International

12. Horta BL, Victora CG. Short-term effects of breastfeeding: a systematic review on the benefits of breastfeeding on diarrhoea and pneumonia.2013. WHO Press, Geneva, Switzerland.

13. Turin CG, Ochoa TJ. The role of maternal breast milk in preventing infantile diarrhoea in the developing world. Current Tropical Medicine Reports, 1(2), 97-105.

14. Chaturvedi P, Warren CD, Altaye M, Morrow AL, Ruiz-Palacios G, Pickering LK, Newburg, DS. Fucosylated human milk oligosaccharides vary between individuals and over the course of lactation. 2001. Glycobiology, 11(5), 365-372.

15. Lamberti, LM, Walker CLF, Noiman A, Victora C, Black RE. Breastfeeding and the risk of diarrhoea morbidity and mortality. 2011. BioMed Central Public Health, 11(15), 1-12.

16. Ogbo FA, Eastwood J, Page A, Arora A, McKenzie, A, Jalaludin, B, Tennant E, Miller E, Noble JKJ, Chaves K, Jones JM, Smoleniec J, Chay P, Smith B, Oei J-L, Short K, Collie L, Kemp L, Raman S, Woolfenden S, Clark T, Blight V, Eapen V \& for the Early Years Research Group. Prevalence and determinants of cessation of exclusive breastfeeding in the early postnatal period in Sydney, Australia. 2017.International Breastfeeding Journal, 12(16), 1-10

17. Yalcin SS, Berde AS, Yalcin S. Determinants of exclusive breastfeeding in sub-Saharan Africa: A multilevel approach. 2016. Paediatric and Perinatal Epidemiology, 30(5), 439-449.

18. Pruss-Ustun A, Bartram J, Clasen T, Colford J, Cumming O, Curtis V, Bonjour S, Dangour AD, De France J, Fewtrell L, Freeman MC, Gordon B, Hunter PR, Johnston RB, Mathers C, Mausezahl D, Medlicott K, Neira M, Stocks M, Wolf J, Cairncross S. Burden of disease from inadequate water, sanitation and hygiene in low - and middle-income settings: A retrospective analysis of data from 145 countries. 2014. Tropical Medicine and International Health, 19(8), 894-905.

Page $12 / 14$ 
19. Kumi-Kyereme A, Amo-Adjei J. Household wealth, residential status and the incidence of diarrhoea among children under-five years in Ghana. 2016. Journal of Epidemiology and Global Health, 6, 131-140.

20. Mengistie B, Berhane $Y$, Worku A. Prevalence of diarrhoea and associated risk factors among children underfive years of age in Eastern Ethiopia: A cross-sectional study. 2013. Open Journal of Preventive Medicine, 3, 446-453.

21. Siziya S, Muula AS, Rudatsikira E. Correlates of diarrhoea among children below the age of 5 years in Sudan. 2013. African Health Sciences, 13(2), 376-383.

22. Fotso JC, Cleland J, Mberu B, Mutua M, Elungata P. Birth spacing and child mortality: An analysis of prospective data from the Nairobi urban health and demographic surveillance system. 2013. Journal of Biosocial Science, 45(6), 779-798.

23. Rasooly MH, Saeed KMI, Noormal B, Aman I, Arnorld F, Govindasamy P, Rutstein S, Winter R. The effectives of birth intervals on causes of under-five mortality in Afghanistan. 2013. DHS Working Paper, Measure DHS, ICF International

24. Acharya D, Singh JK, Adhikari M, Gautam S, Pandey P, Dayal V. Association of water handling and child feeding practice with childhood diarrhoea in rural community of Southern Nepal. 2018. Journal of Infection and Public Health, 11(1), 69-74

25. Hunter PR, Risebro H, Yen M, Lefebvre H, Lo C, Hartemann P, Longuet C, Jaquenoud F. Water source and diarrhoeal disease risk in children under five years old in Cambodia: A prospective diary-based study. 2013. BMC Public Health, 13(1145), 1-9.

26. Plate DK, Strassmann BI, Wilson ML. (2004). Water sources are associated with children diarrhoea prevalence in rural east-central Mali. Tropical Medicine International Health, 9(3), 416-425.

\section{Figures}

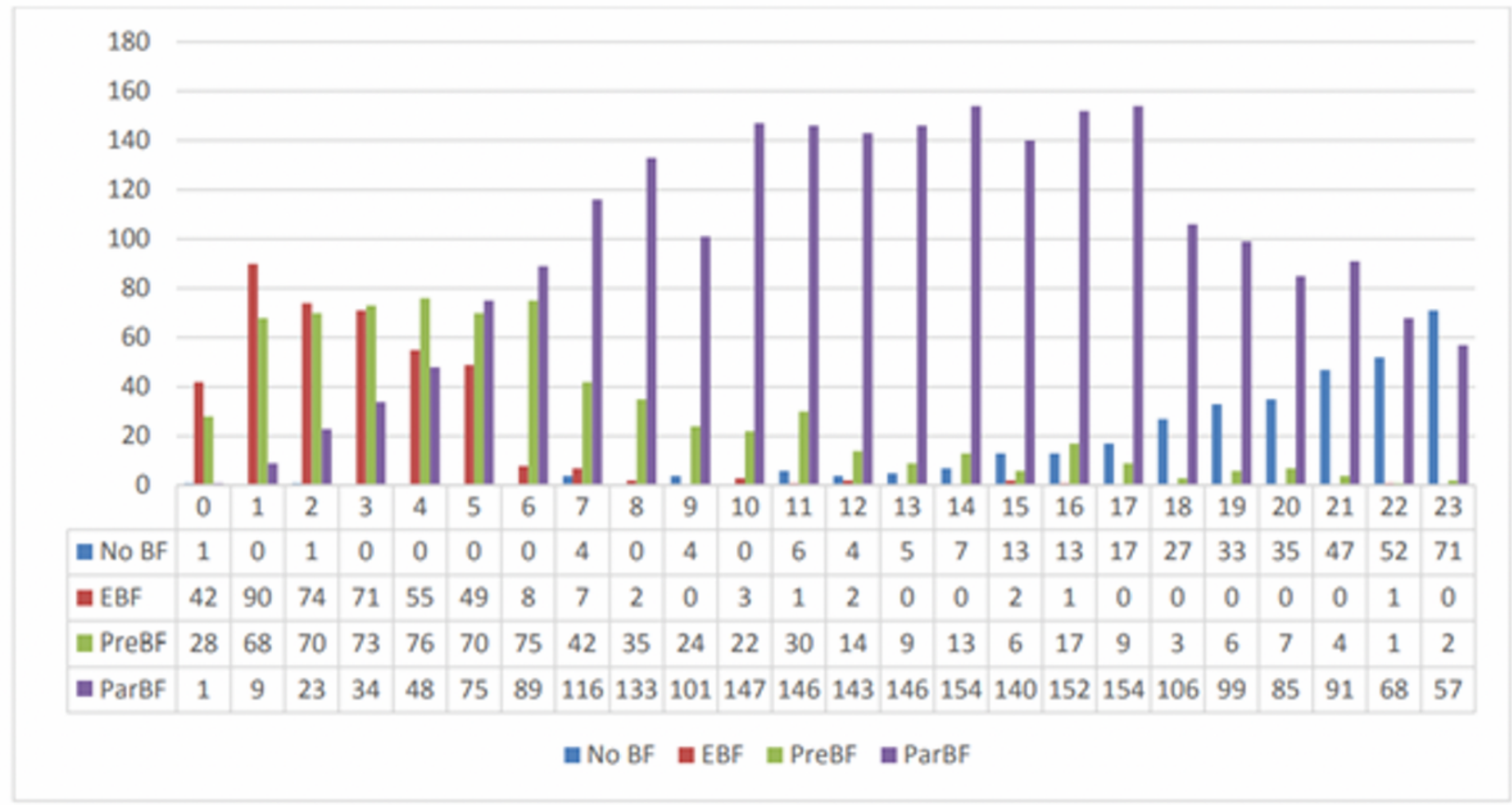

Page $13 / 14$ 


\section{Figure 1}

Age of child (0-23 months) and breastfeeding practices. No BF - No Breastfeeding; EBF - Exclusive Breastfeeding; PreBF - Predominant Breastfeeding; ParBF-Partial Breastfeeding 